\title{
Improved High-Temperature Leakage in High-Density MIM Capacitors by Using a TiLaO Dielectric and an Ir Electrode
}

\author{
C. H. Cheng, H. C. Pan, H. J. Yang, C. N. Hsiao, C. P. Chou, \\ S. P. McAlister, Senior Member, IEEE, and Albert Chin, Senior Member, IEEE
}

\begin{abstract}
We have fabricated high- $\kappa$ TaN/Ir/TiLaO/TaN metal-insulator-metal capacitors. A low leakage current of $6.6 \times 10^{-7} \mathrm{~A} / \mathrm{cm}^{2}$ was obtained at $125{ }^{\circ} \mathrm{C}$ for $24-\mathrm{fF} / \mu \mathrm{m}^{2}$ density capacitors. The excellent device performance is due to the combined effects of the high- $\kappa$ TiLaO dielectric, a high workfunction Ir electrode, and large conduction band offset.
\end{abstract}

Index Terms-High- $\kappa$, Ir, metal-insulator-metal (MIM), TiLaO.

\section{INTRODUCTION}

$\mathbf{T}$ HERE is a continuing demand to increase the capacitance density $\left(\varepsilon_{0} \kappa / \mathrm{t}_{\kappa}\right)$ of the metal-insulator-metal (MIM) capacitors [1]-[16]. To achieve this, the MIM devices have evolved by using higher $\kappa$ dielectrics such as $\mathrm{SiN}$ [3], [4], $\mathrm{Al}_{2} \mathrm{O}_{3}$ [6], [7], $\mathrm{Ta}_{2} \mathrm{O}_{5}$ [5], $\mathrm{HfO}_{2}$ [8]-[10], $\mathrm{Nb}_{2} \mathrm{O}_{5}$ [11], TiTaO [12], [13], and $\mathrm{SrTiO}_{3}$ (STO) [14]-[16]. Unfortunately, increasing the $\kappa$ value usually decreases the conduction band offset $\left(\Delta E_{C}\right)$ with respect to the metal electrode. For STO [17], $\Delta E_{C}$ can even be slightly negative. A low $\Delta E_{C}$ leads to unwanted leakage current for a MIM device at high temperatures [16], where such increase in the operational temperature is unavoidable due to the increased circuit density and higher power dissipation. Although STO shows higher $\kappa$ values and good device characteristics, a higher process temperature $>450{ }^{\circ} \mathrm{C}$ for nanocrystal formation and thicker thickness to reduce leakage are necessary. This exceeds the maximum temperature $\left(400^{\circ} \mathrm{C}\right)$ permitted for backend integration [14]-[16].

Here, we report low thermal leakage TiLaO MIM capacitors using a high work-function Ir electrode, which are processed at $400{ }^{\circ} \mathrm{C}$. We measured leakage currents of $1 \times 10^{-7}$ and $6.6 \times$ $10^{-7} \mathrm{~A} / \mathrm{cm}^{2}$ at $1 \mathrm{~V}$ at $25^{\circ} \mathrm{C}$ and $125^{\circ} \mathrm{C}$, respectively; these

Manuscript received August 16, 2007; revised September 26, 2007. This work was supported in part by NSC 95-2221-E-009-275 of Taiwan. The review of this letter was arranged by Editor A. Wang.

C. H. Cheng and C. P. Chou are with the Department of Mechanical Engineering, National Chiao-Tung University, Hsinchu 300, Taiwan, R.O.C

H. C. Pan and C. N. Hsiao are with the Instrument Technology Research Center, National Applied Research Laboratories, Hsinchu, Taiwan, R.O.C.

H. J. Yang and A. Chin are with the Department of Electronics Engineering, National Chiao-Tung University, Hsinchu 300, Taiwan, R.O.C. (e-mail: albert_achin@hotmail.com; achin@cc.nctu.edu.tw).

S. P. McAlister is with the National Research Council of Canada, Ottawa, ON K1A 0R6, Canada.

Color versions of one or more of the figures in this letter are available online at http://ieeexplore.ieee.org.

Digital Object Identifier 10.1109/LED.2007.909612 currents are lower than those in the previously reported $\mathrm{TiTaO}$ and $400{ }^{\circ} \mathrm{C}$-processed STO capacitors.

\section{EXPERIMENTAL PROCEDURE}

The high- $\kappa$ TiLaO MIM capacitors were fabricated on standard Si wafers. To permit VLSI backend integration, the process began with depositing a $2-\mu$ m-thick $\mathrm{SiO}_{2}$ isolation layer on the Si substrates. Then, a 50-nm TaN was deposited on a 200-nm Ta layer by sputtering and used as the lower capacitor electrode. The TaN surface was then given a plasma treatment to increase the oxidation resistance before the high- $\kappa$ deposition and postdeposition annealing (PDA) [5], [6]. A 15-nm-thick $\mathrm{Ti}_{x} \mathrm{La}_{1-x} \mathrm{O}(\mathrm{x} \sim 0.67)$ film was deposited by PVD, followed by a $400-{ }^{\circ} \mathrm{C}$ PDA in an oxygen ambient to reduce the defects and the leakage current [3] (the TiLaO thickness was later measured by cross-sectional transmission electron microscopy). Finally, 20-nm Ir and/or 50-nm TaN were deposited and patterned to form the top electrode. A large capacitor size of $100 \mu \mathrm{m} \times$ $100 \mu \mathrm{m}$ was chosen to avoid any variations in dimensions arising from lithography. The devices were characterized by $C-V$ and $J-V$ measurements.

\section{RESUlTS AND Discussion}

In Fig. 1, we show the $C-V, J-V$, and thermal-stability characteristics of TaN/TiLaO/TaN and TaN/Ir/TiLaO/TaN devices. A comparison with other data is summarized in Table I. A high capacitance density of $24-24.5 \mathrm{fF} / \mu \mathrm{m}^{2}$ was measured for the TiLaO MIM devices, which gives a high- $\kappa$ value of $\sim 45$ for the TiLaO dielectric. A leakage current of $2.2 \times 10^{-6} \mathrm{~A} / \mathrm{cm}^{2}$ at $-1 \mathrm{~V}$ was measured for the TaN/TiLaO/TaN MIM capacitor close to that of an Ir/TiTaO/TaN device (Table I) with a slightly lower capacitance density. Since the work function of the TaN on TiLaO is $\sim 0.7 \mathrm{~V}$ lower than that of Ir on TiTaO, the comparable leakage current indicates that the TiLaO is a better choice for MIM capacitors than TiTaO. This is confirmed by the five times lower leakage current of $1 \times 10^{-7} \mathrm{~A} / \mathrm{cm}^{2}$ in the TaN/Ir/TiLaO/TaN device compared with the Ir/TiTaO/TaN capacitor. This improved leakage current, at a comparable capacitance density, is due to the higher $\Delta E_{C}$ between metal and high- $\kappa$ interface, which lowers the leakage current exponentially. A similar lower leakage current was also reported by adding higher $\Delta E_{C} \mathrm{Al}_{2} \mathrm{O}_{3}$ into $\mathrm{HfO}_{2} \mathrm{MIM}$ capacitor [9]. The 


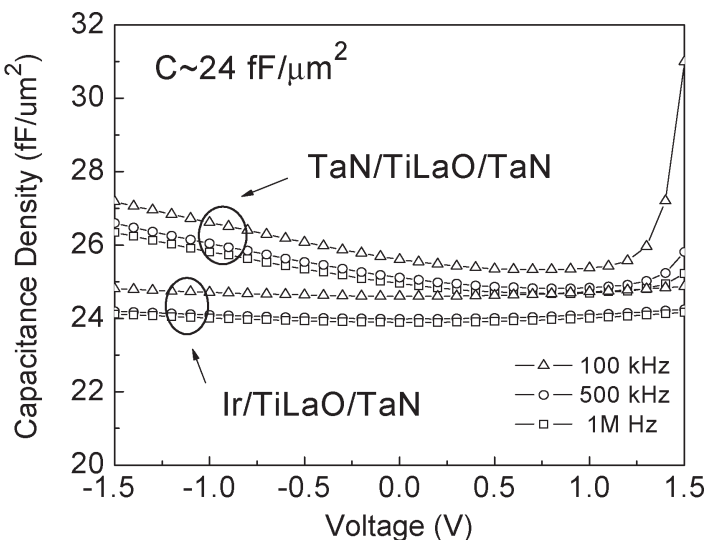

(a)

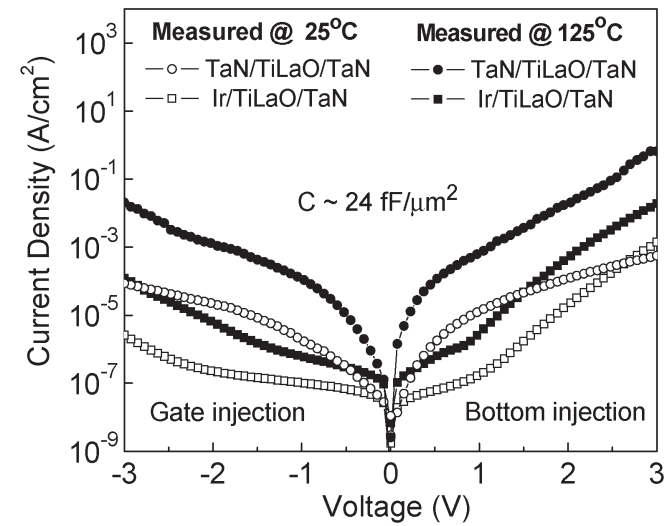

(b)

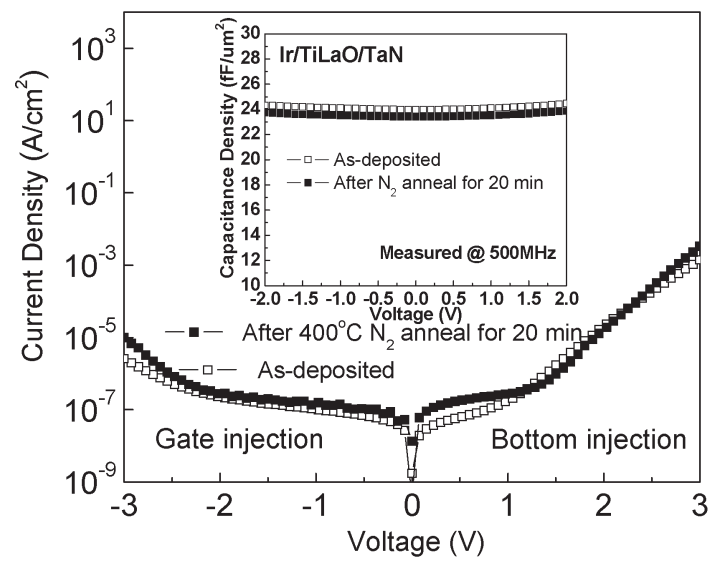

(c)

Fig. 1. (a) $C-V$, (b) $J-V$, and (c) thermal-stability characteristics of $\mathrm{TaN} / \mathrm{TiLaO} / \mathrm{TaN}$ and $\mathrm{TaN} / \mathrm{Ir} / \mathrm{TiLaO} / \mathrm{TaN}$ MIM capacitors measured at various frequencies, at $25^{\circ} \mathrm{C}$ and $125^{\circ} \mathrm{C}$. The thermal-stability test was performance at $400{ }^{\circ} \mathrm{C}$ for $20 \mathrm{~min}$ in an ambient $\mathrm{N}_{2}$.

small changes of $J-V$ and $C-V$, after $400-{ }^{\circ} \mathrm{C} \mathrm{N}_{2}$ annealing, indicate that the thermal stability is acceptable. Note that good thermal stability was reported for metal-gate/high- $\kappa$ pMOS for Ir on HfAlON at Rapid Thermal Anneal (RTA) temperatures up to $900{ }^{\circ} \mathrm{C}$ [17].

A larger $\Delta E_{C}$ at the metal/high- $\kappa$ interface is very important at $125{ }^{\circ} \mathrm{C}$, which is a temperature required for both DRAM and nonvolatile memory [18]. This is shown in the comparison with STO: The leakage current (at $-1 \mathrm{~V}$ ) of a $400{ }^{\circ} \mathrm{C}$ formed $\mathrm{Ni} / \mathrm{STO} / \mathrm{TaN}$ capacitor increased from $2 \times 10^{-7}$ to $5 \times$
TABLE I

COMPARISON OF MIM CAPACITORS WITH VARIOUS DiELECTRICS AND METAL ElECTRODES

\begin{tabular}{|c|c|c|c|c|c|c|c|c|}
\hline & $\begin{array}{c}\mathrm{HfO}_{2} \\
{[8]}\end{array}$ & \begin{tabular}{|c} 
Tb- \\
$\mathrm{HfO}_{2}$ \\
{$[10]$}
\end{tabular} & $\begin{array}{c}\mathrm{Al}_{2} \mathrm{O}_{3-} \\
\mathrm{HfO}_{2} \\
{[9]}\end{array}$ & $\begin{array}{c}\mathrm{TiTaO} \\
{[12]-[13]}\end{array}$ & $\begin{array}{l}\text { STO } \\
{[16]}\end{array}$ & $\begin{array}{l}\text { STO } \\
{[14]}\end{array}$ & \multicolumn{2}{|c|}{ TiLaO } \\
\hline $\begin{array}{l}\text { Process } \\
\text { Temp. }\left({ }^{\circ} \mathrm{C}\right)\end{array}$ & 400 & 400 & 400 & 400 & 400 & 450 & \multicolumn{2}{|c|}{400} \\
\hline $\begin{array}{c}\text { Top } \\
\text { Electrode }\end{array}$ & $\mathrm{Ta}$ & $\mathrm{Ta}$ & TaN & Ir & $\mathrm{Ni}$ & $\mathrm{TaN}$ & $\mathrm{TaN}$ & Ir \\
\hline $\begin{array}{l}\text { Work-function } \\
(\mathrm{eV})\end{array}$ & 4.2 & 4.2 & 4.6 & 5.27 & 5.1 & 4.6 & 4.6 & 5.27 \\
\hline $\begin{array}{l}\text { C Density } \\
\left(\mathrm{fF} / \mu \mathrm{m}^{2}\right)\end{array}$ & 13 & 13.3 & 12.8 & 23 & 25.2 & 28 & 24.5 & 24 \\
\hline $\begin{array}{c}\mathrm{J}\left(\mathrm{A} / \mathrm{cm}^{2}\right) \\
\left(a 25^{\circ} \mathrm{C}\right.\end{array}$ & $\begin{array}{l}6 \times 10^{-7} \\
(2 \mathrm{~V})\end{array}$ & $\begin{array}{l}1 \times 10^{-7} \\
(2 \mathrm{~V})\end{array}$ & $\begin{array}{c}8 \times 10^{-9} \\
(2 \mathrm{~V})\end{array}$ & $\begin{array}{c}2 \times 10^{-6} \\
(1 \mathrm{~V}) \\
2 \times 10^{-5} \\
(2 \mathrm{~V}) \\
\end{array}$ & $\begin{array}{c}2 \times 10^{-7} \\
(1 \mathrm{~V}) \\
8 \times 10^{-6} \\
(2 \mathrm{~V})\end{array}$ & $\begin{array}{l}3 \times 10^{-8} \\
(2 \mathrm{~V})\end{array}$ & $\begin{array}{c}2.2 \times 10^{-6} \\
(1 \mathrm{~V})\end{array}$ & $\begin{array}{c}1 \times 10^{-7} \\
(1 \mathrm{~V}) \\
2.3 \times 10^{-7} \\
(2 \mathrm{~V})\end{array}$ \\
\hline $\begin{array}{l}\mathrm{J}\left(\mathrm{A} / \mathrm{cm}^{2}\right) \\
\text { (a) } 125^{\circ} \mathrm{C}\end{array}$ & $\begin{array}{l}2 \times 10^{-6} \\
(1 V)\end{array}$ & $\begin{array}{l}2 \times 10^{-7} \\
(2 \mathrm{~V})\end{array}$ & $\begin{array}{c}6 \times 10^{-9} \\
(1 \mathrm{~V}) \\
5 \times 10^{-8} \\
(2 \mathrm{~V}) \\
\end{array}$ & - & $\begin{array}{c}5 \times 10^{-6} \\
(1 \mathrm{~V})\end{array}$ & - & $1.3 \times 10^{-4}$ & $\begin{array}{c}6.6 \times 10^{-7} \\
(1 \mathrm{~V}) \\
6.7 \times 10^{-6} \\
(2 \mathrm{~V})\end{array}$ \\
\hline
\end{tabular}

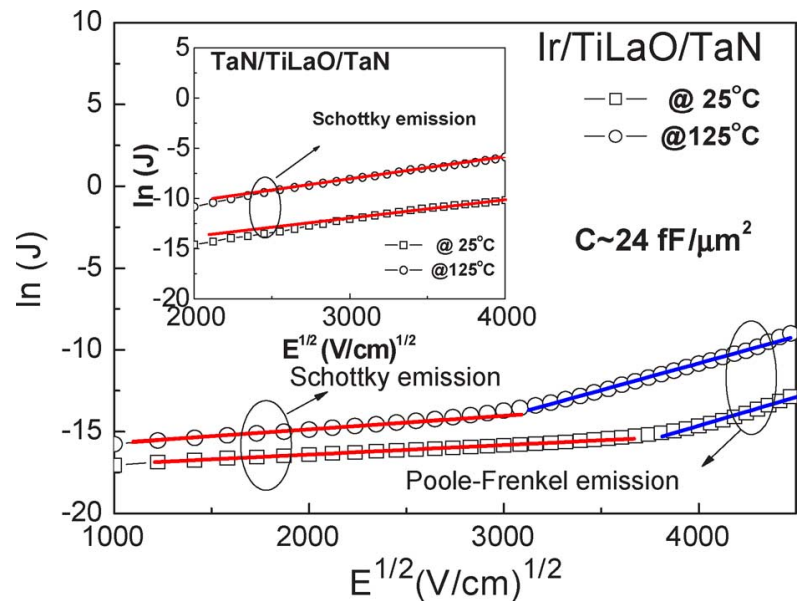

Fig. 2. Measured and simulated $J-E^{1 / 2}$ of an $\mathrm{Ir} / \mathrm{TiLaO} / \mathrm{TaN}$ capacitor. A TaN/TiLaO/TaN device is shown, for comparison, in the inset.

$10^{-6} \mathrm{~A} / \mathrm{cm}^{2}$, from $25{ }^{\circ} \mathrm{C}$ to $125{ }^{\circ} \mathrm{C}$ (Table I), whereas in the $\mathrm{TaN} / \mathrm{Ir} / \mathrm{TiLaO} / \mathrm{TaN}$ capacitor, it only increased from $1 \times 10^{-7}$ to $6.6 \times 10^{-7} \mathrm{~A} / \mathrm{cm}^{2}$. Although the work function of the $\mathrm{Ir}$ electrode $(5.27 \mathrm{eV})$ is slightly higher than $\mathrm{Ni}(5.1 \mathrm{eV})$, the improved $125-{ }^{\circ} \mathrm{C}$ leakage current can be attributed to the large $\Delta E_{C}$. We note that $\mathrm{La}_{2} \mathrm{O}_{3}$ has the highest $\Delta E_{C}$ with respect to $\mathrm{Si}(2.3 \mathrm{eV})$ compared with $\mathrm{HfO}_{2}(1.5 \mathrm{eV}), \mathrm{ZrO}_{2}(1.4 \mathrm{eV})$, $\mathrm{Ta}_{2} \mathrm{O}_{5}(0.3 \mathrm{eV})$, and STO ( $\left.-0.1 \mathrm{eV}\right)$ [19].

To investigate the current conduction mechanism we plot, in Fig. $2, \ln (J)$ versus $E^{1 / 2}$ for the TaN/Ir/TiLaO/TaN MIM capacitors

$$
\begin{aligned}
& J \propto \exp \left(\frac{\gamma E^{1 / 2}-V_{b}}{k T}\right) \\
& \gamma=\left(\frac{e^{3}}{\eta \pi \varepsilon_{0} K_{\infty}}\right)^{1 / 2} .
\end{aligned}
$$

Here, $K_{\infty}$ is the high-frequency dielectric constant $\left(=n^{2}\right)$. The refractive index $n$ is 2.57 or 1.9 for $\mathrm{TiO}_{2}$ or $\mathrm{La}_{2} \mathrm{O}_{3}$ [20], 


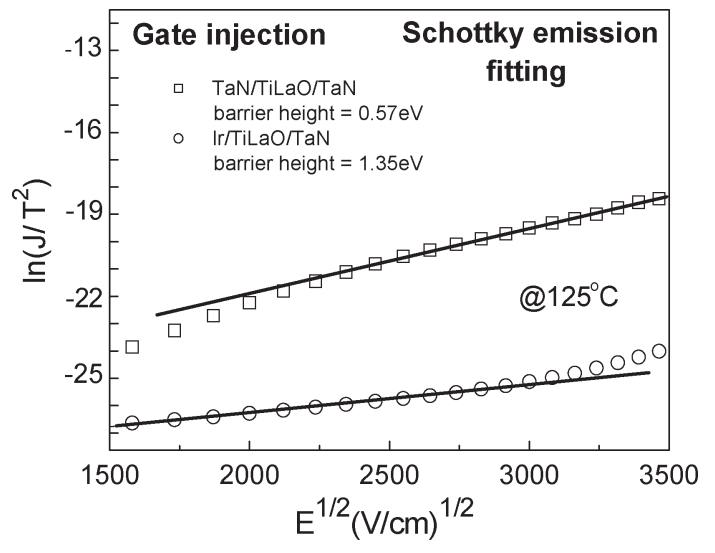

Fig. 3. $J / T^{2}-E^{1 / 2}$ plots of TaN/TiLaO/TaN and TaN/Ir/TiLaO/TaN MIM capacitors.

and $\eta$ is 1 or 4 for Schottky emission (SE) or Frenkel-Poole (FP) conduction, respectively. The data fitting suggests that the current conduction mechanism of the $\mathrm{TaN} / \mathrm{Ir} / \mathrm{TiLaO} / \mathrm{TaN}$ device changes from SE at low electric fields to FP at higher fields. In contrast, the TaN/TiLaO/TaN devices fit an SE description at both low and high fields.

The SE barrier height $\left(V_{b}\right)$ at $125{ }^{\circ} \mathrm{C}$ was determined from $J / T^{2}-E^{1 / 2}$ plots (Fig. 3). Values for $V_{b}$ were 0.57 and $1.35 \mathrm{eV}$ for TiLaO devices at $125{ }^{\circ} \mathrm{C}$ with TaN and Ir top electrodes, respectively. The large $V_{b}$ difference explains the reduced leakage current and the weaker temperature dependence in the TaN/Ir/TiLaO/TaN devices. Thus, a low leakage current at high temperature can be obtained in MIM capacitors by combining a high- $\kappa$ dielectric, having a high $\Delta E_{C}$, with a high work-function metal electrode.

\section{CONCLUSION}

A high capacitance density and low leakage current at $125{ }^{\circ} \mathrm{C}$ have been achieved in Ir/TiLaO/TaN MIM capacitors. The device-processing temperature of $400{ }^{\circ} \mathrm{C}$ would enable them to be integrated into the VLSI backend technology and be used in multiple functions associated with system-on-a-chip.

\section{REFERENCES}

[1] The International Technology Roadmap for Semiconductors: Semicond. Ind. Assoc., 2005. [Online]. Available: www.itrs.net

[2] C.-M. Hung, Y.-C. Ho, I.-C. Wu, and K. O, "High-Q capacitors implemented in a CMOS process for low-power wireless applications," in Proc. IEEE MTT-S Int. Microw. Symp. Dig., 1998, pp. 505-511.

[3] J. A. Babcock, S. G. Balster, A. Pinto, C. Dirnecker, P. Steinmann, R. Jumpertz, and B. El-Kareh, "Analog characteristics of metal-insulatormetal capacitors using PECVD nitride dielectrics," IEEE Electron Device Lett., vol. 22, no. 5, pp. 230-232, May 2001.
[4] C. H. Ng, K. W. Chew, and S. F. Chu, "Characterization and comparison of PECVD silicon nitride and silicon oxynitride dielectric for MIM capacitors," IEEE Electron Device Lett., vol. 24, no. 8, pp. 506-508, Aug. 2003.

[5] T. Ishikawa, D. Kodama, Y. Matsui, M. Hiratani, T. Furusawa, and D. Hisamoto, "High-capacitance $\mathrm{Cu} / \mathrm{Ta}_{2} \mathrm{O}_{5} / \mathrm{Cu}$ MIM structure for $\mathrm{SoC}$ applications featuring a single-mask add-on process," in IEDM Tech. Dig., 2002, pp. 940-942.

[6] S. B. Chen, J. H. Lai, A. Chin, J. C. Hsieh, and J. Liu, "High-density MIM capacitors using $\mathrm{Al}_{2} \mathrm{O}_{3}$ and $\mathrm{AlTiO}_{x}$ dielectrics," IEEE Electron Device Lett., vol. 23, no. 4, pp. 185-188, Apr. 2002.

[7] S. B. Chen, J. H. Lai, K. T. Chan, A. Chin, J. C. Hsieh, and J. Liu, "Frequency-dependent capacitance reduction in high-k $\mathrm{AlTiO}_{x}$ and $\mathrm{Al}_{2} \mathrm{O}_{3}$ gate dielectrics from IF to RF frequency range," IEEE Electron Device Lett., vol. 23, no. 4, pp. 203-205, Apr. 2002.

[8] X. Yu, C. Zhu, H. Hu, A. Chin, M. F. Li, B. J. Cho, D.-L. Kwong, P. D. Foo, and M. B. Yu, "A high-density MIM capacitor $\left(13 \mathrm{fF} / \mu \mathrm{m}^{2}\right)$ using $\mathrm{ALD} \mathrm{HfO}_{2}$ dielectrics," IEEE Electron Device Lett., vol. 24, no. 2 , pp. 63-65, Feb. 2003.

[9] H. Hu, S. J. Ding, H. F. Lim, C. Zhu, M. F. Li, S. J. Kim, X. F. Yu, J. H. Chen, Y. F. Yong, B. J. Cho, D. S. H. Chan, S. C. Rustagi, M. B. Yu, C. H. Tung, A. Du, D. My, P. D. Fu, A. Chin, and D. L. Kwong, "High performance $\mathrm{HfO}_{2}-\mathrm{Al}_{2} \mathrm{O}_{3}$ laminate MIM capacitors by ALD for RF and mixed signal IC applications," in IEDM Tech. Dig., 2003, pp. 379-382.

[10] S. J. Kim, B. J. Cho, M.-F. Li, C. Zhu, A. Chin, and D. L. Kwong, " $\mathrm{HfO}_{2}$ and Lanthanide-doped $\mathrm{HfO}_{2}$ MIM capacitors for $\mathrm{RF} /$ mixed IC applications," in VLSI Symp. Tech. Dig., 2003, pp. 77-78.

[11] S. J. Kim, B. J. Cho, M. B. Yu, M.-F. Li, Y.-Z. Xiong, C. Zhu, A. Chin, and D. L. Kwong, "High capacitance density $\left(>17 \mathrm{fF} / \mu \mathrm{m}^{2}\right) \mathrm{Nb}_{2} \mathrm{O}_{5}$-based MIM capacitors for future RF IC applications," in VLSI Symp. Tech. Dig., 2005 , pp. 56-57.

[12] K. C. Chiang, A. Chin, C. H. Lai, W. J. Chen, C. F. Cheng, B. F. Hung, and C. C. Liao, "Very high- $\kappa$ and high density TiTaO MIM capacitors for analog and RF applications," in VLSI Symp. Tech. Dig., 2005, pp. 62-63.

[13] K. C. Chiang, C. H. Lai, A. Chin, T. J. Wang, H. F. Chiu, J. R. Chen, S. P. McAlister, and C. C. Chi, "Very high density $\left(23 \mathrm{fF} / \mu \mathrm{m}^{2}\right)$ RF MIM capacitors using high- $\kappa$ TiTaO as the dielectric," IEEE Electron Device Lett., vol. 26, no. 10, pp. 728-730, Oct. 2005.

[14] K. C. Chiang, C. C. Huang, A. Chin, W. J. Chen, H. L. Kao, M. Hong, and J. Kwo, "High performance micro-crystallized $\mathrm{TaN} / \mathrm{SrTiO}_{3} / \mathrm{TaN}$ capacitors for analog and RF applications," in VLSI Symp. Tech. Dig., 2006, pp. 126-127.

[15] K. C. Chiang, C. C. Huang, A. Chin, G. L. Chen, W. J. Chen, Y. H. Wu, A. Chin, and S. P. McAlister, "High performance $\mathrm{SrTiO}_{3} \mathrm{MIM}$ capacitors for analog applications," IEEE Trans. Electron Devices, vol. 53, no. 9, pp. 2312-2319, Sep. 2006.

[16] K. C. Chiang, C. H. Cheng, H. C. Pan, C. N. Hsiao, C. P. Chou, A. Chin, and H. L. Hwang, "High-temperature leakage improvement in Metal-Insulator-Metal capacitors by work-function tuning," IEEE Electron Device Lett., vol. 28, no. 3, pp. 235-237, Mar. 2007.

[17] D. S. Yu, A. Chin, C. H. Wu, M.-F. Li, C. Zhu, S. J. Wang, W. J. Yoo, B. F. Hung, and S. P. McAlister, "Lanthanide and Ir-based dual metalgate/HfAlON CMOS with large work-function difference," in IEDM Tech. Dig., 2005, pp. 649-652.

[18] C. H. Lai, A. Chin, H. L. Kao, K. M. Chen, M. Hong, J. Kwo, and C. C. Chi, "Very low voltage $\mathrm{SiO}_{2} / \mathrm{HfON} / \mathrm{HfAlO} / \mathrm{TaN}$ memory with fast speed and good retention," in VLSI Symp. Tech. Dig., 2006, pp. 54-55.

[19] J. Robertson, "Band offsets of wide-band-gap oxides and implications for future electron devices," J. Vac. Sci. Technol. B, Microelectron. Process. Phenom., vol. 18, no. 3, pp. 1785-1791, May 2000.

[20] F. C. Chiu, H. W. Chou, and J. Y.-M. Lee, "Electrical conduction mechanisms of metal $/ \mathrm{La}_{2} \mathrm{O}_{3} / \mathrm{Si}$ structure," J. Appl. Phys., vol. 97, no. 10, pp. 103 503-1-103 503-5, May 2005. 